\title{
The use of misoprostol in outpatient treatment of abortions in the first quarter of pregnancy in Dakar
}

\author{
M. M. Niang${ }^{1}$, N. A. Fall Augowet ${ }^{2}$, D. Diallo ${ }^{1}$, M. Thiam ${ }^{3}$, J. C. Moreau ${ }^{4}$, C. T. Cisse ${ }^{1}$
}

\author{
${ }^{1}$ Department of Obstetrics and Gynecology, Cheikh Anta Diop Univesity of Dakar, Social Hygiene Institute Hospital, \\ Dakar, Senegal \\ ${ }^{2}$ Department of Obstetrics and Gynecology, Aristide Le Dantec Hospital, Senegal \\ ${ }^{3}$ Department of Obstetrics and Gynecology, Univesity of Thies, Senegal \\ ${ }^{4}$ Department of Obstetrics and Gynecology, Cheikh Anta Diop Univesity of Dakar, Aristide Le Dantec Hospital
}

Received: 30 August 2017

Accepted: 25 September 2017

\section{*Correspondence:}

Dr. M. M. Niang,

E-mail: mansniang@ hotmail.com

Copyright: () the author(s), publisher and licensee Medip Academy. This is an open-access article distributed under the terms of the Creative Commons Attribution Non-Commercial License, which permits unrestricted non-commercial use, distribution, and reproduction in any medium, provided the original work is properly cited.

\begin{abstract}
Background: The objective of this study was to compare the effectiveness of misoprostol comparing to MVA in support of abortion from the first quarter.

Methods: This was a prospective, descriptive and analytical study (case-control study) made between January $1^{\text {st }}$ and December $31^{\text {st }}, 2015$ in a level 1 maternity in Dakar.

Results: The study included316 first trimester abortions (158 were treated with misoprostol and 158 with MVA). The epidemiological profile was a woman aged on average 28.5 years and nulliparous $(37 \%)$. The mean gestational age was 8 weeks 6 days. The rate of complete uterine evacuation was comparable in both groups (93\% for misoprostol versus $94.3 \%$ for MVA) with a non-significant p-value. Side effects found (40.8\%) were minor. The hospital stay averaged two hours in the misoprostol group against 24 hours for MVA. Anaemia was more common in the MVA group $(44.1 \%)$ than in the misoprostol group $(23.6 \%)(\mathrm{p}=0.0006)$. The cost of treatment with misoprostol (5620 CFA francs) was on average four times less than that of MVA $(21,623$ CFA francs).

Conclusions: Misoprostol can be seen as a credible alternative in the management of first quarter abortions because of its many advantages including its effectiveness, its easiness to be used in ambulatory, its low cost and safety.
\end{abstract}

Keywords: MVA, Miscarriages, Misoprostol

\section{INTRODUCTION}

Around the world, $15 \%$ of pregnancies end up with abortions. ${ }^{1}$ In Senegal, abortions are responsible for $8 \%$ of maternal death. ${ }^{2}$ Most of these abortions are managed with manual vacuum aspiration (MVA). It is a highly efficient method but it requires skilled health personnel, an appropriate and sterile equipment and anaesthesia. ${ }^{3}$ Medical methods such misoprostol can also be used to manage abortion; they do not require many resources and can be administered by paramedical providers. ${ }^{4}$ In Senegal, there is no consensus over the use of misoprostol as a means of managing early abortions. Our study was aimed at comparing the efficiency of misoprostol with that of the MVA for first trimester abortion management.

\section{METHODS}

This study was conducted in a level 1 Maternity in Dakar. It was a prospective, analytical and descriptive casecontrol study conducted from $1^{\text {st }}$ January to $31^{\text {st }}$ December 2015. It included all pregnant women which were subject to a first trimester abortion with a 
gestational age of 13 weeks of amenorrhea or less (WA). It does not include pregnant women with more than 13 weeks of amenorrhea nor does it include cases of scarred uterus, molar pregnancies or illegally induced abortions. Patients were submitted to a treatment with a $600 \mu \mathrm{g}$ dose of misoprostol administered through vaginal route or treated with manual vacuum aspiration. Patients were previously distributed between the two groups basing on drawing lots. The outcome was a complete uterine evacuation within 48 hours. We used the 20.0 version of the SPSS software to enter and analyze data.

\section{RESULTS}

\section{Frequency}

Over the study period, we identified 651 abortions among which there were 5582 cases of obstetrical admissions, an $11.7 \%$ frequency rate.

Among these cases, $316(48.5 \%)$ fulfilled the inclusion criteria.

Table 1: Patients characteristics according to the treatment used in the management of first trimester abortions in a level one hospital in Dakar in 2015.

\begin{tabular}{|c|c|c|c|}
\hline Variables studied & Misoprostol $(\mathrm{n}=158)$ & MVA $(n=158)$ & p \\
\hline Mean age & 28 ans 9 mois $( \pm 1.44)$ & 28 ans 6 mois $( \pm 6.33)$ & \\
\hline Marital status & & & \multirow[t]{4}{*}{ NS } \\
\hline Single & $7(4.4 \%)$ & $1(0.6 \%)$ & \\
\hline Married & $149(94.3 \%)$ & $156(98.7 \%)$ & \\
\hline Divorced & $2(1.3 \%)$ & $1(0.6 \%)$ & \\
\hline Parity & & & \multirow[t]{4}{*}{ NS } \\
\hline Nullipare & $59(37.3 \%)$ & $58(36.7 \%)$ & \\
\hline Few previous deliveries & $88(55.7 \%)$ & $88(55.7 \%)$ & \\
\hline Multipare & $11(7 \%)$ & $12(7.6 \%)$ & \\
\hline Professional activity & & & \multirow[t]{3}{*}{0.003} \\
\hline Without & $115(72.8 \%)$ & $136(86.1 \%)$ & \\
\hline With & $43(27.2 \%)$ & $22(13.9 \%)$ & \\
\hline Geographic origin & & & \multirow[t]{3}{*}{ NS } \\
\hline In the district & $75(47.47 \%)$ & $69(43.67 \%)$ & \\
\hline Out of the district & $83(52.53 \%)$ & $89(56.33 \%)$ & \\
\hline
\end{tabular}

Table 2: Pregnancy characteristics according to the treatment used in the management of first trimester abortions in a level one hospital in Dakar in 2015.

\begin{tabular}{|c|c|c|c|}
\hline $\begin{array}{l}\text { Variables } \\
\text { studied }\end{array}$ & $\begin{array}{l}\text { Misoprostol } \\
(\mathrm{n}=158)\end{array}$ & $\begin{array}{l}\text { MVA } \\
(n=158)\end{array}$ & p \\
\hline Mean age & $\begin{array}{l}28 \text { years } 9 \text { months } \\
( \pm 1.44)\end{array}$ & $\begin{array}{l}28 \text { years } 6 \\
\text { months }( \pm 6.33)\end{array}$ & \\
\hline \multicolumn{3}{|c|}{ Antenatal care } & \multirow{3}{*}{ NS } \\
\hline Done & $10(6.3 \%)$ & $15(9.5 \%)$ & \\
\hline Not done & 148 & 143 & \\
\hline \multicolumn{3}{|c|}{ Gestational age (weeks) } & \multirow{4}{*}{ NS } \\
\hline$<6$ & 9 & 11 & \\
\hline $6-12$ & 142 & 146 & \\
\hline $12-13$ & 7 & 1 & \\
\hline
\end{tabular}

\section{Patients features}

Patients were aged 28 years and 9 months on average in the misoprostol group against 28 years and 9 months in the MVA group. As for their marital status, as well as the equality between them and their geographical origin, there was no substantial difference between the two groups (Table 1).

\section{Characteristics of the current pregnancy}

The majority of patients had not begun to receive their prenatal care yet. In the misoprostol group, only 10 patients $(6.3 \%)$ had already received prenatal care, against 15 patients $(9.5 \%)$ in the MVA group. The current phase of pregnancy progress at the moment of the abortion was comparable in the two groups with a mean gestational age of $8 \mathrm{WA}$ and 6 days (Table 2).

\section{Results of the treatment and length of the hospital stay}

We recorded a $93 \%$ rate of successful abortions in the misoprostol group against a $94.3 \%$ rate in the MVA group. The length of hospital stay was equal in the two groups. The majority of patients stayed less than 12 hours at the maternity $(99.4 \%$ within the misoprostol group against $94.9 \%$ within the MVA group) (Table 3).

Side effects, most commonly with uterine cramps and headache, were found in $40.8 \%$ of patients in the Misoprostol group. Anaemia was more frequent in the AMIU group $(44.1 \%)$ than in the Misoprostol group 
$23.6 \%$ with a statistically significant difference $(\mathrm{p}=$ 0.0006) (Table 4).

Table 3: Treatment outcome and length of hospital stay by therapeutic method chosen in the management of first trimester abortions in a level one hospital in Dakar in 2015.

\begin{tabular}{|c|c|c|c|}
\hline $\begin{array}{l}\text { Variables } \\
\text { studied }\end{array}$ & $\begin{array}{l}\text { Misoprostol } \\
(\mathbf{n}=\mathbf{1 5 8 )}\end{array}$ & $\begin{array}{l}\text { MVA } \\
(\mathbf{n}=158)\end{array}$ & $\mathbf{p}$ \\
\hline \multicolumn{3}{|c|}{ Treatment outcome } & \multirow{3}{*}{ NS } \\
\hline Success & $147(93 \%)$ & $149(94.3 \%)$ & \\
\hline Failure & $11(7 \%)$ & $9(5.7 \%)$ & \\
\hline \multicolumn{3}{|c|}{ Length of hospital stay } & \multirow{4}{*}{ NS } \\
\hline$<12$ & $157(99.4 \%)$ & $150(94.9 \%)$ & \\
\hline $12-24$ & - & $2(1.3 \%)$ & \\
\hline$>24$ & $1(0.6 \%)$ & $6(3.8 \%)$ & \\
\hline
\end{tabular}

\section{Side effects and complications}

During the study, some side effects, mainly uterine cramps and headaches were noticed among $40.8 \%$ of the patients within the misoprostol group. Anemia was more common among the MVA group $(44.1 \%)$ than in the misoprostol group $(23.6 \%)$ with a statistically significant difference $(\mathrm{p}=0.0006)$ (Table 4$)$.

Table 4: Haemoglobin rate according to the treatment used in the management of first trimester abortions in a level one hospital in Dakar in 2015.

\begin{tabular}{|c|c|c|c|}
\hline Variables studied & Misoprostol & MVA & $\mathbf{P}$ \\
\hline \multicolumn{3}{|c|}{ Haemoglobin level (g/dl) } & \multirow{4}{*}{0.0006} \\
\hline$<7$ & - & $6(4.87 \%)$ & \\
\hline $7-11$ & $30(23.6 \%)$ & $48(39.2 \%)$ & \\
\hline$>11$ & $97(76.4 \%)$ & $69(56.09)$ & \\
\hline
\end{tabular}

Table 5: Cost of treatment depending on the chosen treatment method and the number of proceedings in the management of first trimester abortions in a level one hospital in Dakar in 2015.

\begin{tabular}{|c|c|c|}
\hline \multirow{2}{*}{$\begin{array}{l}\text { Number of } \\
\text { proceedings }\end{array}$} & \multicolumn{2}{|c|}{ Treatment cost (CFA francs) } \\
\hline & MVA & Misoprostol \\
\hline 1 proceeding & 21623 & 5620 \\
\hline 2 proceedings & 29123 & 6580 \\
\hline
\end{tabular}

\section{Cost of treatment}

The cost of the misoprostol treatment amounted to 5,620 CFA francs. It included: $960 \mathrm{CFA}$ francs spent in the purchasing of three misoprostol tablets, 1,537 CFA francs to pay for local antiseptics and 3123 CFA francs to buy uterotonic. Then, there was a second procedure which required three other misoprostol tablets thus raising the cost up to $6580 \mathrm{CFA}$ francs. As for the MVA treatment which is four times higher than the misoprostol protocol, it amounted to 21623 CFA francs. This sum included the surgery itself $(10,000$ CFA francs $)$, the medical equipment (7500 CFA francs), and antibiotics used during the post abortion phase (1000 CFA francs). A second procedure required the purchasing of new material raising the total cost up of MVA to 29,123 CFA francs (Table 5).

\section{DISCUSSION}

The epidemiological profile of this study was a young woman aged 28 and a half on average, nulliparous (37\%) and married. We can find the same profile in previous studies conducted on abortion in Senegal. Indeed, Gueye, Faye and Cissé found a mean age of 28.5 in their respective studies. ${ }^{5-7}$ All the patients we treated presented an amenorrhea of 13 weeks or less with a gestational age of $8 \mathrm{WA}$ and 6 days. The same observation was made across the literature on this area where the majority of authors conducted studies on first trimester abortions. ${ }^{8-10}$ One of the factors that explain this similarity is that, as the pregnancy progresses, the efficiency of misoprostol for abortion management decreases. ${ }^{9}$

The success rate was comparable in the two groups since it was $93 \%$ within the misoprostol group against $94.3 \%$ within the MVA group with a low p-value reflecting similarities in the two treatments in terms of efficiency. In many recent studies, the success rates amounted to $80 \% .{ }^{11}$ For example, Bagratee and Tang, using a $600 \mu \mathrm{g}$ dose of misoprostol through vaginal route with the possibility to renew the doses within 7 days, respectively obtained success rates of $87 \%$ and $87.5 \% .^{12,13}$ With a $800 \mu \mathrm{g}$ dose of moistened misoprostol administered through vaginal route and an which was to be renewed one week later if the abortion was not complete, Bughalo obtained a success rate of $87,1 \%$ after a single dose and $92 \%$ after two doses. ${ }^{8}$ In his study, Jain used a $800 \mu \mathrm{g}$ dose of moistened misoprostol administered through vaginal route and which was to be repeated each 24 hours up to three times if the abortion did not happen. ${ }^{10}$

In this study, the success rates amounted to $72 \%, 86 \%$ and $88 \%$ obtained respectively after one dose, two doses and three doses. As a result, we can assert that the protocol we resorted to for the treatment of first trimester abortion is as much efficient as those used by other authors in previous studies with similar or even higher doses. This observation consolidated our decision to use this method. Moreover, the availability of ultrasound scan, ideally performed within 48 hours, allowed us to improve the method's efficiency and to reduce the period of support. In previous studies, this period ranged from 7 to 10 days whereas, in the present study, it did not exceed 48 hours with a lower morbidity for the misoprostol group. ${ }^{8-10}$ Indeed, anemia, which is the most common observed complications was more frequent within the MVA group $(44.1 \%)$ than in the Misoprostol group $(23.6 \%)$ with a statistically significant difference ( $\mathrm{p}=$ 0.0006). There was severe anemia in $4.9 \%$ of the cases treated through MVA whereas none of the patients treated with Misoprostol presented a severe anemia. 
However, this gap is probably due to bias in the selection process if we bear in mind that all the cases of serious abortions with abundant metrorrhagia and/or hemodynamic instability required an urgent uterine evacuation based on MVA.

Present study also dealt with the cost of first trimester abortions management. This cost is four times lower for the Misoprostol-based treatment (5620 CFA francs) than for the MVA treatment (21623 CFA francs), regardless to the number of procedures. In the study conducted by Gueye, the costs ranged from 2240 to 81900 CFA francs, with an average cost of 18470 CFA francs. ${ }^{5}$ This lower cost, along with the other clinical benefits, constitutes a strong argument in favor of the use of Misoprostol for first trimester abortions management. Thus, Misoprostol is a credible alternative to MVA treatment in countries with limited resources such as ours, where the cost of the health care is mainly endorsed by patients themselves.

\section{CONCLUSION}

The use of Misoprostol in first semester abortions management has a similar efficiency compared to MVA: its lower cost, its good tolerance as well as the possibility to use it in the treatment of outpatient cases make it a reliable alternative for the treatment of incomplete first quarter abortions.

Funding: No funding sources

Conflict of interest: None declared

Ethical approval: The study was approved by the Institutional Ethics Committee

\section{REFERENCES}

1. Weeks A. Expectative or surgical treatment in case of miscarriage. WHO Reproductive Health Library. Consulté le 15 Septembre 2014. Available at http://apps.who.Int/rhl/pregnancy_childbirth/antenata 1_care/miscarriage/awcom $1 / \mathrm{fr} /$

2. Center for Training and Research in Reproductive Health (CEFOREP). Review of the literature on unsafe abortions in Senegal. Dakar Avril. 1998:70

3. Clark W, Shannon C, Winikoff B. Misoprostol for uterine evacuation in induced abortion and pregnancy failure. Expert Rev Obstet Gynecol. 2007;2(1):67-108.

4. American College of Obstetricians and Gynecologists. ACOG Committee Opinion No. 427:
Misoprostol for postabortion care. Obstet Gynecol. 2009;113(2)(1):465-8.

5. Gueye M. Extension of post-abortion care in the regional hospitals of Kaolack and Diourbel and in the health center of Sokone. Thesis Med Dakar. 2006;63:27.

6. Faye KG. Interest of manual intrauterine aspiration in the management of pregnancies stopped at the gynecological and obstetric clinic of Dakar. Thesis Med Dakar. 2005;42:111.

7. Cissé CT, Faye KG, Moreau JC. First-trimester abortions in Chu de Dakar: Interest of manual aspiration intra-uterine. Med Trop. 2007;67:163-6.

8. Bugalho A, Mocumbi S, Faúndes A, David E. Termination of pregnancies of $<6$ weeks gestation with a single dose of $800 \mu \mathrm{g}$ of vaginal misoprostol. Contracept. 2000;61:47-50.

9. Esteve CJ, Varela L, Velazco A, Tanda R, Cabezas E, Sánchez C. Early abortion with $800 \mu \mathrm{g}$ of misoprostol by the vaginal route. Contracept. 1999;59; 219-225.

10. Jain JK, Dutton C, Harwood B, Meckstroth KR, Mishell DR. A prospective randomize, doubleblinded, placebo-controlled trial comparing mifepristone and vaginal misoprostol to vaginal misoprostol alone for elective termination of early pregnancy. Human Reprod. 2002;17(6):1477-82.

11. Paul B, Shelley C, Kurus. Provision of medical abortion: an introductory manual. Deuxième Edition Gynuity Health Projects (Deuxieme Edition), New York, NY 10010 USA; 2009.

12. Bagratee JS, Khullar V, Regan L, Moodley J, Kagoro H. A randomized controlled trial comparing medical and expectant management of first trimester miscarriage. Human Reprod. 2004;19(2):266-71.

13. Tang OS, Lau WN, Ng EH, Lee SW, Ho PC. A prospective randomized study to compare the use of repeated doses of vaginal and sublingual misoprostol in the management of first trimester silent miscarriages. Human Reprod. 2003;18:176-81.

Cite this article as: Niang MM, Augowet NAF, Diallo D, Thiam M, Moreau JC, Cisse CT. The use of misoprostol in outpatient treatment of abortions in the first quarter of pregnancy in Dakar. Int J Reprod Contracept Obstet Gynecol 2017;6:4782-5. 